\title{
Heavy drinking is associated with deficient response inhibition in women but not in men
}

Citation for published version (APA):

Nederkoorn, C., Baltus, M., Guerrieri, R., \& Wiers, R. W. H. J. (2009). Heavy drinking is associated with deficient response inhibition in women but not in men. Pharmacology, Biochemistry and Behavior, 93, 331-336. https://doi.org/10.1016/j.pbb.2009.04.015

Document status and date:

Published: 01/01/2009

DOI:

10.1016/j.pbb.2009.04.015

Document Version:

Publisher's PDF, also known as Version of record

Document license:

Taverne

Please check the document version of this publication:

- A submitted manuscript is the version of the article upon submission and before peer-review. There can be important differences between the submitted version and the official published version of record.

People interested in the research are advised to contact the author for the final version of the publication, or visit the DOI to the publisher's website.

- The final author version and the galley proof are versions of the publication after peer review.

- The final published version features the final layout of the paper including the volume, issue and page numbers.

Link to publication

\footnotetext{
General rights rights.

- You may freely distribute the URL identifying the publication in the public portal. please follow below link for the End User Agreement:

www.umlib.nl/taverne-license

Take down policy

If you believe that this document breaches copyright please contact us at:

repository@maastrichtuniversity.nl

providing details and we will investigate your claim.
}

Copyright and moral rights for the publications made accessible in the public portal are retained by the authors and/or other copyright owners and it is a condition of accessing publications that users recognise and abide by the legal requirements associated with these

- Users may download and print one copy of any publication from the public portal for the purpose of private study or research.

- You may not further distribute the material or use it for any profit-making activity or commercial gain

If the publication is distributed under the terms of Article $25 \mathrm{fa}$ of the Dutch Copyright Act, indicated by the "Taverne" license above, 


\title{
Heavy drinking is associated with deficient response inhibition in women but not in men
}

\author{
Chantal Nederkoorn ${ }^{\mathrm{a}, *}$, Marcus Baltus ${ }^{\mathrm{a}}$, Ramona Guerrieri ${ }^{\mathrm{a}}$, Reinout W. Wiers ${ }^{\mathrm{b}}$ \\ a Department of Clinical Psychological Science, Maastricht University, Maastricht, the Netherlands \\ ${ }^{\mathrm{b}}$ Faculty of Social and Behavioural Sciences, University of Amsterdam, Amsterdam, the Netherlands
}

\section{A R T I C L E I N F O}

Available online 3 May 2009

\section{Keywords:}

Alcoholism

Addictive behaviour

Response inhibition

Impulsivity

Gender

\begin{abstract}
A B S T R A C T
Poor response inhibition has been associated with a wide range of problem behaviours, including addictive behaviours, and could represent a general vulnerability factor. Standard tests of response inhibition have used neutral stimuli. Here we tested whether a deficit in response inhibition in heavy drinkers would be stronger for stimuli related to their problem (alcohol) or not. Response inhibition was assessed with a stop signal task, using four classes of pictures: alcohol-related, soft drinks, erotic (control appetitive categories) and neutral pictures. Participants were 32 heavy and 32 light drinkers. An equal amount of men and women were tested in both drinking groups, in view of recent studies reporting that response disinhibition may be most pronounced in heavy drinking women. Main results were first that no domain-specific differences in response inhibition were found in both groups. Second, heavy drinking females showed stronger response inhibition deficits than other groups. Results are discussed in light of a possible gender difference in response inhibition as a risk factor for addictive behaviours.
\end{abstract}

(c) 2009 Elsevier Inc. All rights reserved.

\section{Introduction}

Many recent models of addiction conceptualize the aetiology of addictive behaviours as a combination of relatively strong appetitive responses triggered by addiction-related stimuli and relatively weak executive control over the impulse to use (e.g., Bechara, 2005; Kalivas and Volkow, 2005; Wiers et al., 2007). Addictive behaviour is strongly associated with poor executive functioning and lack of cognitive control over behaviour (Hester and Garavan, 2004, Perry and Carroll, 2008). A central executive top-down function needed for behavioural control is inhibition. Rewarding, appetitive stimuli automatically trigger prepotent approach tendencies, that lead to drug use, unless this in inhibited (Field et al., 2008; Wiers et al., 2009). In order to overrule the first automatic intention to approach stimuli, operations must be stopped and in some cases reorganised to fit the new intention (Logan and Cowan, 1984; Band and van Boxtel, 1999). Individual differences in the ease with which the executive system can inhibit a prepotent response reflect variety in behavioural control. This implies that ineffective response inhibition makes people vulnerable for excessive use of rewarding substances and might therefore be a cause of addiction. Indeed, a number of recent studies found that

\footnotetext{
* Corresponding author. Department of Clinical Psychological Science, Maastricht University, P.O. Box 616, 6200 MD Maastricht, the Netherlands. Tel.: +31 43 3881925; fax: +31433884199 .

E-mail address: c.nederkoorn@psychology.unimaas.nl (C. Nederkoorn).
}

alcohol and drug use are better predicted by measures of relatively automatic appetitive processes in individuals with relatively poor executive control (Grenard et al., 2008; Houben and Wiers, 2009; Thush et al., 2008) and similar findings have been reported for other impulsive behaviours, including aggression, candy consumption, and sexual impulses (Hofmann et al., 2008).

Relatively weak response inhibition and impulsivity have been proposed as a general vulnerability factor for addictive behaviours (e.g., Sher et al., 1991; Verdejo-Garcia et al., 2008). Indeed, many studies have reported that childhood disorders involving high impulsivity like Attention Deficit Hyperactivity Disorder (ADHD) and Conduct Disorder, to be related to an increased risk for substance abuse (e.g., Elkins et al., 2007; Sher et al., 1991; Tarter et al., 2004). Moreover, response inhibition prospectively predicted alcohol-related problems at the ages 15-17 (Nigg et al., 2006). In another line of research, children at increased risk for alcohol abuse (offspring from an alcoholic parent) have been compared to control children. Children at risk show less effective response inhibition (Nigg et al., 2004; Sher et al., 1991; Wiers et al., 1998) and less behavioural control (Sher et al., 2005). This appears to have a genetic basis: children at risk for alcohol abuse manifest disruption in the laterality of the orbitofrontal cortex (OFC) volume compared to control children, which is related to genetic variation (Hill et al., 2009). The reduced white matter in the right OFC was related to increased impulsivity and might predispose the children to engage in risky behaviours, including alcohol abuse (Hill et al., 2009). Animal studies have demonstrated that mice selected for higher alcohol consumption showed less effective response inhibition, 
without any exposure to alcohol (e.g., Wilhelm et al., 2007). Together, these findings suggest that poor response inhibition predisposes individuals to addictive behaviours (review: Verdejo-Garcia et al., 2008).

Although there is increasing evidence of involvement in the vulnerability for addiction of impulsivity, behavioural undercontrol and relatively weak response inhibition, there is also emerging evidence for a more complex picture. Not only can weak response inhibition lead to drug use, repeated drug use can also negatively influence response inhibition. In several controlled studies, acute alcohol intake has been found to diminish response inhibition, whereas primary responding remained intact (e.g. Fillmore and Vogel-Sprott, 2006; Perry and Carroll, 2008). Prolonged alcohol intake has been associated with several functional and structural abnormalities in brain areas, including the frontal lobes (Goldstein et al., 2001; Moselhy et al., 2001) as well as the impairment of several executive functions such as response inhibition (Hildebrandt et al., 2004; Rubio et al., 2007). There is also some evidence (primarily from animal studies) that impairments are stronger when alcohol and drug use takes place during adolescence as compared with adult use of the same amount (Crews et al., 2000). These two vulnerability factors are likely to enhance each other: insufficient response inhibition may lead to substance abuse, which in turn leads to less effective response inhibition. There is growing evidence that the link between alcohol use and inhibition is indeed reciprocal (see Wiers et al., 2007 for a review).

Repeated drug use not only impairs cognitive functioning, but also leads to conditioned responses to cues associated with the drug of abuse (Havermans et al., 2007). For example, alcohol-related stimuli elicit enhanced craving (Carter and Tiffany, 1999) and faster approach responses than control stimuli in alcoholics, compared to control participants (Field et al., 2008), as well as in heavy drinkers, especially when carrying a g-allele in the OPRM1 gene (Wiers et al., 2009). Exposure to relevant drug cues also leads to increased activity in frontolimbic areas in the brain (Goldstein and Volkow, 2002) in drug addicts, as opposed to controls. Goldstein and Volkow (2002) suggest in their model that craving or drug anticipation leads to a decrease of inhibitory control. Therefore, it seems conceivable that drug users are even less able to inhibit responses to stimuli related to their specific drug than to stimuli that are irrelevant to their addiction, the main hypothesis of this study.

A small number of recent studies are directly relevant for this research question. Elicited food craving did not influence response inhibition in restrained eaters, although their performance was poorer on the inhibition task in general than the control group (Nederkoorn et al., 2004). However, neutral stimuli and not food related stimuli were used. It is thus unknown how the participants' task performance would have been influenced by food related stimuli. Noël et al. (2005, 2007a) used a variety of the Go-NoGo paradigm and instructed participants to react as fast as possible to a word of one category (alcohol or neutral), while inhibiting their response to words of the other category. Participants performed a number of blocks of each category, presented in blocks of two with the same instruction. This permitted the comparison of continued instruction to a switch of instruction (e.g. from respond to alcohol, not to not-alcohol, to respond to notalcohol, not to alcohol). Comparing alcohol abusers with healthy controls, they found that the alcohol abusers showed more commission and omission errors in general and even more pronounced when the Go stimulus was related to alcohol (Noël et al., 2005). Comparable results were found in detoxified alcoholics: they made more commission errors in general (i.e. they responded more often to the NoGo stimulus compared with healthy controls), and this difference was more pronounced when the NoGo stimulus was neutral. This might suggest an enhanced preparedness to detect alcohol words (Noël et al., 2007b). Note that Field and Cole (2007) offered an alternative explanation of these results: avoidance or impaired cognitive processing of alcohol-related words, as indexed by slower reaction times to respond to those words when the words function as targets. Rose and Duka (2008) studied the effect of acute alcohol intake on inhibitory processes on neutral and alcohol-related stimuli using a modified Stroop paradigm. They found that although alcohol affected interference inhibition compared with placebo, no differential effects on neutral and alcohol stimuli were found. However, the social drinkers reacted slower to alcohol-related stimuli in a Go-NoGo task, irrespective of acute alcohol preload, which could indicate that alcohol stimuli are more salient to social drinkers. In sum, heavy drinking has been associated with a number of cognitive biases towards alcohol cues (attentional bias, approach bias), as well as with relatively weak response inhibition, but it is not clear whether weak response inhibition in heavy drinkers would be more pronounced for alcoholrelated stimuli, the main hypothesis of the present study.

In the present study we tested response inhibition in light and heavy drinkers using the stop signal task, which allows for a more straightforward interpretation than commission errors on the GoNoGo task (Field and Cole, 2007; Noël et al., 2007b). In this task, participants do not need to categorize stimuli, but must respond to a single stimulus unless an auditory stop signal is presented. We used pictures as primary stimuli because pictures have been shown to better evoke reward-related responses than words (Townshend and Duka, 2001; Lees et al., 2005). Our main hypothesis was tested by using pictures of alcoholic drinks as well as neutral pictures. In addition, we tested other appetitive stimuli, such as soft drinks and erotic stimuli, to test whether heavy drinkers would show impaired response inhibition for appetitive stimuli in general.

In addition to the primary hypothesis regarding the specificity of response inhibition deficits in heavy drinkers, the effect of gender was investigated. Men and women differ in their drinking pattern, in their transition from initial use to dependence (Zilberman et al., 2003) and in risk factors of alcohol use (Flensborg-Madsen et al., 2007). Moreover, the effect of alcohol on inhibitory control has been shown to be moderated by gender. Men display greater impairment of inhibitory control when receiving an acute dose of alcohol compared to women (Fillmore and Weafer, 2004). In the long run the effects of alcohol on response inhibition seem to be reversed in men and women. Townshend and Duka (2005) found that female binge drinkers compared to non-binge drinkers showed stronger deficits in executive cognitive function associated with inhibitory control. This was not found in men. We therefore expected that female heavy drinkers would show greater deficits in response inhibition than male heavy drinkers.

\section{Method}

\subsection{Participants}

Sixty-four undergraduate students from the Maastricht University (32 women) participated. Participants were recruited through advertisements posted at the university. A brief telephone interview was administered to interested students, asking them about their age, gender and weekly alcohol use. Only students who consumed at least 1 drink per week were included. Mean age was 21.05 years $(S D=2.31)$. Three participants were excluded from the analysis: one male participant with missing data on the self-report questionnaires and two female participants who had errors on the stop signal task exceeding three standard deviations from the mean.

\subsection{Measures}

\subsubsection{Alcohol use}

Alcohol use was measured with a questionnaire, based on the timeline follow-back method (Sobell and Sobell, 1990). Participants were asked to indicate how many alcohol drinks of different types they had during each day of the past week, and how many drinks they 
typically have on each day of the week (Wiers et al., 1997). The measure derived was the total number of alcohol units consumed in the last week. It should be noted that in the Netherlands 1 unit equals $10 \mathrm{~g}$ alcohol whereas this is $14 \mathrm{~g}$ alcohol in the US.

\subsubsection{Alcohol-related problems}

Alcohol-related problems were assessed with the AUDIT, the World Health Organization screening instrument of alcohol use disorders (Saunders et al., 1993). It consists of 10 questions $(\alpha=0.65)$, the first three questions measuring alcohol use and the following seven questions assessing alcohol-related problems. Cut-offs: 8+ hazardous drinking, $11+$ likely alcohol use disorder.

\subsubsection{Binge drinking}

Binge drinking was assessed by having participants report the number of days on which they drank more than 5 units of alcohol $(=50 \mathrm{~g})$ on one occasion during the past two weeks (the same threshold was used for men and women).

\subsubsection{Trait impulsiveness}

Trait impulsiveness was assessed by the Barratt Impulsiveness Scale (BIS; Patton et al., 1995), a self-report questionnaire which consists of 30 items answered on a 4-point scale. Scores range from 30 to 120 with higher scores indicating more impulsiveness. Three subscales measure three different sorts of impulsiveness: motor impulsiveness (acting without thinking), attentional impulsiveness (not focusing on the task at hand, cognitive instability) and nonplanning impulsiveness (lack of orientation toward the future).

\subsubsection{Response inhibition}

Response inhibition was measured by an adapted version of the Stop signal task (Logan et al., 1997). This task involves two concurrent tasks; a Go task, which is a choice reaction time task and a stop task, occurring on $25 \%$ of the Go trials and involving a stop signal that tells subjects to inhibit their response to the Go task.

In this version participants had to decide as fast as possible whether a picture on the computer screen was either in portrait or landscape view during the Go trials (cf. Wiers et al., 2009). Participants pressed a left button on a button box with their left index finger when the picture was in landscape and a right button with their right index finger when the picture was in portrait view. Four categories of pictures were used, each consisting of 10 different pictures: neutral (shades of grey), soft drinks (e.g. cola), alcohol (e.g. beer) and mild erotic (e.g. a kissing couple). Each picture was presented both in portrait and in landscape view. Because the erotic pictures could possibly influence overall performance, it was decided to present alcohol, soft drinks and neutral pictures in the first block and alcohol, neutral and erotic pictures in the second. The two blocks were presented in succession, with a short break of a few seconds. The pictures were presented in the centre of the screen or $180 \mathrm{~mm}$ above or below the centre, in a randomized balanced order.

In $25 \%$ of the trials (the stop trials), an auditory stop signal ( $1000 \mathrm{~Hz}, 100 \mathrm{~ms}$ ) was presented through headphones. This stop signal indicated to the participants that they had to inhibit their response and refrain from pressing a button. This stop signal was presented at fixed delays of 150, 200, 250 and $300 \mathrm{~ms}$ after the presentation of the Go stimulus. Delays were used in random order and equally often, thus each delay time was used in $6.25 \%$ of the trials. It is more difficult to inhibit responding when the stop signal is presented after a longer delay. The use of fixed delays was chosen, rather than the often used dynamically adjusted delay because this allows to directly compare response inhibition on different Go stimuli with the same delay.

To calculate the stop signal reaction time (SSRT) the following procedure was used (adapted from Scheres et al., 2003). First, all reaction times on the Go trials of a given participant were rank ordered, from fastest to slowest. Second, the $n$th percentage reaction time was picked, $n$ being defined by the probability of responding given a stop signal. When a participant responded on $30 \%$ of the trials with a stop signal, the 30th percentile reaction time in the rankordered distribution was selected. This reaction time is an estimate of the time at which the stop process runs to completion, relative to the onset of the Go signal. Third, the average stop signal interval (mean of the four fixed delay times, is $225 \mathrm{~ms}$ ) was subtracted from this reaction time to estimate SSRT. Higher SSRTs indicate that a participant needs more time to inhibit a response, reflecting less efficient response inhibition.

Participants received two practice blocks of 16 trials (with neutral stimuli) to practice responding on the Go stimuli. No stop signals were presented. After the second block (and every block thereafter) the participants received feedback on their mean reaction time and number of errors, and they were instructed to respond as fast as possible. Next, participants received a practice block of 32 trials in which a stop signal was presented in $25 \%$ of the trails. The actual task consisted of two test blocks, each consisting of 3 blocks of 96 trials. Between blocks, participants were allowed to take a short break of a few seconds.

\subsection{Procedure}

Participants were tested in groups of one to five people, each seated in a separate cubicle. They signed an informed consent prior to participation and then started the adjusted stop signal task. Afterwards they filled in the questionnaires, were thanked for participation and received their fee $(7.50 €)$. We certify that all applicable institutional and governmental regulations concerning the ethical use of human volunteers were followed during this research. Approval of the Maastricht University Ethical Committee was obtained.

\section{Results}

\subsection{Group characteristics}

The alcohol measures correlated highly (AUDIT and binge drinking: $r=0.073$, AUDIT and alcohol use: $r=0.77, p<0.001$; binge drinking and alcohol use: $r=0.87, p<0.001)$. Given the high correlation and the frequency of occasional binge drinking in the Dutch student populations, we decided to use alcohol use as the primary classification variable and checked the main results for alternative classifications (binge drinker or not). Based on a median split on alcohol use (11.5 units for females and 12.5 for males), participants were classified as heavy or light drinkers. Group-scores on the alcohol-related variables are presented in Table 1.

\subsection{Stop signal reaction time}

A 2 (test block) $\times 3$ (picture type) $\times 2$ (gender) $\times 2$ (drinking group) mixed ANOVA with gender and drinking group as between-subject variables and test block and picture type as within-subject variables was used to analyze the stop signal reaction times (SSRT). Means and

Table 1

Group characteristics (mean and SD) on alcohol measures.

\begin{tabular}{|c|c|c|c|c|}
\hline & $\begin{array}{l}\text { Female light } \\
\text { drinkers }\end{array}$ & $\begin{array}{l}\text { Female heavy } \\
\text { drinkers }\end{array}$ & $\begin{array}{l}\text { Male light } \\
\text { drinkers }\end{array}$ & $\begin{array}{l}\text { Male heavy } \\
\text { drinkers }\end{array}$ \\
\hline$n$ & $\overline{15}$ & 15 & 15 & 16 \\
\hline $\begin{array}{l}\text { Alcohol use } \\
\text { (units/last week) }\end{array}$ & $6.1(3.4)^{\mathrm{a}}$ & $17.4(7.4)^{b}$ & $5.1(3.6)^{a}$ & $30.7(15.9)^{\mathrm{C}}$ \\
\hline AUDIT & $7.0(1.8)^{\mathrm{a}}$ & $11.9(3.4)^{\mathrm{b}}$ & $7.1(2.9)^{\mathrm{a}}$ & $14.7(2.6)^{\mathrm{c}}$ \\
\hline Binge days ( $n$ days $>5$ units) & $0.47(0.64)^{\mathrm{a}}$ & $1.73(1.16)^{\mathrm{b}}$ & $0.13(0.35)^{\mathrm{a}}$ & $2.12(1.15)^{b}$ \\
\hline
\end{tabular}

Means not sharing similar subscripts within a row differ at $p<0.05 .1$ unit contains $10 \mathrm{~g}$ alcohol. 
Table 2

Mean (and SD) stop signal task times (in ms) on the different stimuli.

\begin{tabular}{llrlll}
\hline & & $\begin{array}{l}\text { Female light } \\
\text { drinkers }\end{array}$ & $\begin{array}{l}\text { Female heavy } \\
\text { drinkers }\end{array}$ & $\begin{array}{l}\text { Male light } \\
\text { drinkers }\end{array}$ & $\begin{array}{l}\text { Male heavy } \\
\text { drinkers }\end{array}$ \\
\hline SSRT & Neutral & $200.64(45.6)$ & $254.3(87.1)$ & $216.4(64.1)$ & $215.9(56.1)$ \\
session 1 & Soft drink & $213.4(45.2)$ & $240.1(74.9)$ & $217.9(62.8)$ & $209.8(53.2)$ \\
& Alcohol & $196.7(45.9)$ & $250.1(82.7)$ & $228.5(76.3)$ & $210.5(45.7)$ \\
SSRT & Neutral & $193.9(49.4)$ & $254.1(93.4)$ & $194.3(69.7)$ & $185.7(49.7)$ \\
session 2 & Erotic & $204.5(57.9)$ & $240.3(69.8)$ & $217.1(80.3)$ & $193.6(52.2)$ \\
& Alcohol & $200.5(44.8)$ & $245.3(64.4)$ & $195.3(60.0)$ & $186.4(43.5)$ \\
\hline
\end{tabular}

standard deviations are reported in Table 2. A main effect of test block was found: participants had shorter SSRTs in the second test block $(F(1,57)=6.0, p<0.05)$. No main effects of picture type, gender or drinking group were found $(F(2,57)<1.9$, N.S.). The interaction between gender and drinking group was significant $(F(1,57)=4.5$, $p=<0.05$, see Fig. 1). Follow-up analyses indicated that in men, no effect of drinking group was found, $F(1,29)=0.4$, N.S.). In contrast, heavy drinking women demonstrated poorer response inhibition than light drinking women $(F(1,28)=5.5, p<0.05)$. There were no other significant interaction effects $(F(2,57)<3)$. When the analyses were rerun with participants categorized as binge drinkers or non-binge drinkers, the same pattern of results emerged.

\subsection{Errors on the Go trials}

A 2 (session) $\times 3$ (picture type) $\times 2$ (gender $) \times 2$ (drinking group) ANOVA for repeated measures was used to analyze errors on the Go trials. A main effect of session was found: participants made fewer mistakes during the second session ( 10.8 vs. 6.9 errors, $F(1,57)=17.4$ $p<0.001)$. In addition, a main effect of picture type was found: participants made more errors on the soda and erotic pictures than on the other pictures $(F(1,57)=6.4, p<0.01)$. Finally, a main effect of drinking group was found: heavy drinking participants made more errors than light drinking participants ( 11.0 vs. 6.8 errors, $F(1,57)=4.4, p<0.05$ ).

\subsection{Self-report measures}

The self-report measures of impulsiveness (subscales of the Barratt Impulsivity Scale, BIS) were correlated with a 'alcohol severity' factor (calculated by entering last week alcohol use, number of binge drinking days and AUDIT in a factor analysis and combining them in a regression factor score). A significant but modest correlation was found between the planning scale of the BIS and this 'alcohol severity' factor $(r=0.27, p<0.05)$. When looking at males and females separately, the correlations between the planning scale and the alcohol severity factor were comparable ( $r=0.28$ and $r=0.26$ respectively), although in both subgroups not statistically significant.

\section{Discussion}

The main findings of this study can be summarized as follows: first, no overall difference in response inhibition was found between heavy and light drinkers, and our main hypothesis that heavy drinkers would show stronger deficits in response inhibition of alcohol-related stimuli was disconfirmed. Second, heavy drinking women did show stronger deficits in response inhibition than the other groups tested (light drinking women and heavy and light drinking men), confirming our second hypothesis.

Our main finding that there is no content-specific deficit in heavy drinkers appears to contradict the findings of Noël et al. (2007a) who did find that alcoholic patients made more commission errors than controls when reacting to alcohol stimuli compared to neutral stimuli in a Go-NoGo task. In light of the present results it seems more appropriate to interpret their finding as an over-preparedness to detect alcohol-related stimuli rather than as a specific response inhibition deficit towards these stimuli. Domain-specific differences between alcoholics and controls are therefore more likely to be due to differences in attention or approach tendencies (for an overview see Field and Cox, 2008) than to response inhibition. However, it is also possible that the difference in populations studied can explain the findings and that alcohol-specific deficits in response inhibition only appears in people with a clinical alcohol problem and not in heavy drinkers.

The second important finding in this study was a general inhibition problem in female heavy drinkers. Both male and female heavy drinkers appear to make rash decisions in a performance task (commit more errors) and severity of the alcohol problem was found to be related to problems in planning, as measured with the Barratt Impulsivity Scale. This is in line with previous research, showing that this scale is related to alcohol problems (von Diemen et al., 2008) and capable of predicting alcohol use in a longitudinal study, although its effects was partly mediated by positive alcohol expectancies (Fu et al., 2007). However, especially women who drink excessively appear to have poor inhibitory control. This gender effect is in line with the results of Townshend and Duka (2005), who found that female binge drinkers have less inhibitory control than female non-binge drinkers, whereas binge drinking status had no effect in men. Their explanation was that although men drank more alcohol in absolute quantities (as in the present study), the relative impact of alcohol might be larger for females and therefore its effect on the brain more harmful (Townshend and Duka, 2005). An alternative explanation could be that the inhibition problem is a premorbid factor for heavy drinking women. Perhaps for male students the social context is such a strong factor (occasional heavy drinking is almost normative), that heavy drinking is likely to develop irrespective of response inhibition ability (in fact, the one difficult group for us to find in many studies is light drinking males). In females both heavy and light drinking are prevalent; hence there could be more room for selection on possible aetiological factors such as weak inhibitory control. In line with this alternative explanation, previous studies did find different risk factors in boys and girls, with peer pressure being more apparent in boys (Suls and Green, 2003; Piko, 2006) and impulsivity being more apparent in females (Petry et al., 2002). Possibly, poor response inhibition becomes more important in men when social drinking turns into problem drinking and alcoholism. However, since this is a quasi-experimental study it is possible that differences on confounding factors between groups exist.

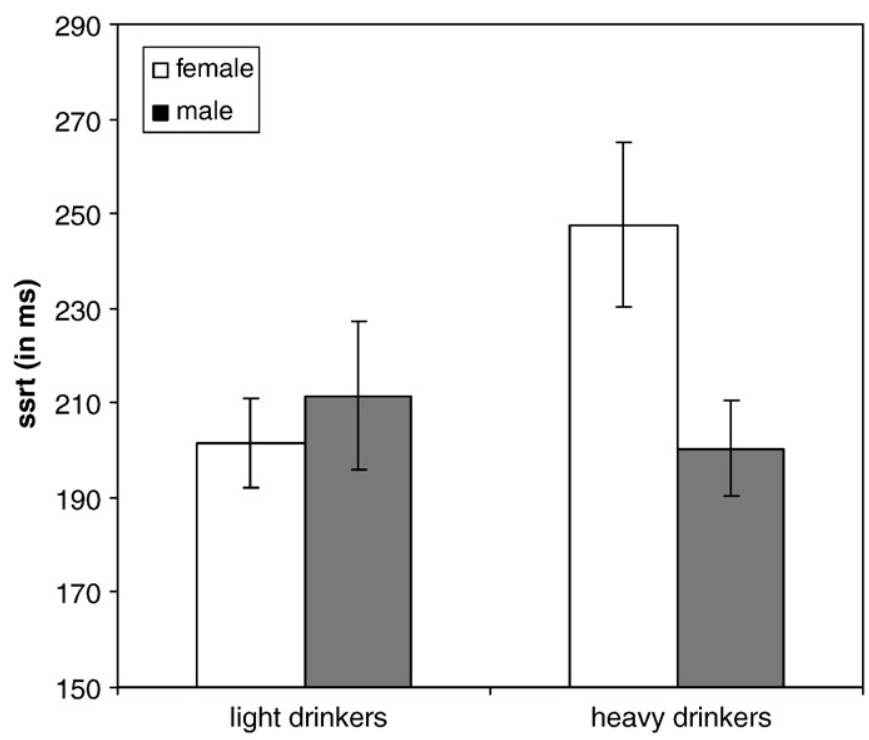

Fig. 1. Mean stop signal reaction time (with SEM) of male and female heavy and light drinkers. 
Clearly, more research on this gender difference and its role in the aetiology of addictive behaviours is needed. In addition, crosssectional research is inadequate to identify the cause and effect of alcohol use and response inhibition. If impulsivity and poor response inhibition indeed constitutes a personality trait which increases the risk for alcohol use, prevention and treatment might be aimed at adjusting impulsivity. A meta-analyses on children with ADHD suggest that stimulant therapy, which reduces impulsivity and improves response inhibition, reduces the risk for subsequent drug and alcohol use disorders (Wilens et al., 2003). Alternative ways of enhancing response inhibition and behavioural control, perhaps by cognitive training programs, might be helpful in preventing addictive behaviour in at risk groups (e.g., Klingberg et al., 2005). The findings of the present study suggest that although problems associated with response inhibition are more prevalent in boys than in girls, girls showing deficits in response inhibition could be at risk for the development of problem drinking.

\section{Acknowledgment}

The authors like to thank Fred Briere for correcting the manuscript.

\section{References}

Band GPH, van Boxtel GJM. Inhibitory motor control in stop paradigms: review and reinterpretation of neural mechanisms. Acta Psychol 1999;101:179-211.

Bechara A. Decision making, impulse control and loss of willpower to resist drugs: a neurocognitive perspective. Nat Neurosci 2005;8:1458-63.

Carter BL, Tiffany ST. Meta-analysis of cue-reactivity in addiction research. Addiction 1999;94:327-40.

Crews FT, Braun CJ, Hoplight B, Switzer III RC, Knapp DJ. Binge ethanol consumption causes differential brain damage in young adolescent rats compared with adult rats. Alcohol Clin Exp Res 2000;24:1712-23.

Elkins IJ, McGue M, lacono WG. Prospective effects of attention-deficit/hyperactivity disorder, conduct disorder, and sex on adolescent substance use and abuse. Arch Gen Psychiatry 2007;64:1145-52.

Field M, Cole J. Do alcohol cues facilitate or impair cognitive processing in recently detoxified alcoholics? Commentary on Noel et al. (2007). Psychopharmacology 2007:192:299-300.

Field M, Cox WM. Attentional bias in addictive behaviors: a review of its development causes, and consequences. Drug Alcohol Depend 2008;97:1-20.

Field M, Kiernan A, Eastwood B, Child R. Rapid approach responses to alcohol cues in heavy drinkers. J Behav Ther Exp Psychiatry 2008;39:209-18.

Fillmore MT, Weafer J. Alcohol impairment of behavior in men and women. Addiction 2004;99:1237-46.

Fillmore MT, Vogel-Sprott M. Acute effects of alcohol and other drugs on automatic and intentional control. In: Wiers RW, Stacy AW, editors. Handbook of implicit cognition and addiction. Thousand Oaks, CA, US: Sage Publications; 2006. p. 293-306.

Flensborg-Madsen T, Knop J, Mortensen EL, Becker U, Grønbaek M. Amount of alcohol consumption and risk of developing alcoholism in men and women. Alcoho Alcohol 2007;42:442-7.

Fu A, Ko H, Wu JY, Cherng B, Cheng C. Impulsivity and expectancy in risk for alcohol use: comparing male and female college students in Taiwan. Addict Behav 2007;32: 1887-96.

Goldstein R, Volkow N. Drug addiction and its underlying neurobiological basis: neuroimaging evidence for the involvement of the frontal cortex. Am J Psych 2002;159:1642-52.

Goldstein RZ, Volkow ND, Wang GJ, Fowler JS, Rajaram S. Addiction changes orbitofrontal gyrus function: involvement in response inhibition. Neuroreport: for rapid communication of neuroscience research, vol. 12. ; 2001. p. 2595-9.

Grenard JL, Ames SL, Wiers RW, Thush C, Sussman S, Stacy AW. Working memory moderates the predictive effects of drug-related associations. Psychol Addict Behav 2008;22:426-32.

Havermans RC, Mulkens S, Nederkoorn C, Jansen A. The efficacy of cue exposure with response prevention in extinguishing drug and alcohol cue reactivity. Behav Intery 2007;22:121-35.

Hester G, Garavan H. Executive dysfunction in cocaine addiction: evidence for discordant frontal, cingulate, and cerebellar activity. J Neurosci 2004;24:11017-22.

Hildebrandt H, Brokate B, Eling P, Lanz M. Response shifting and inhibition, but not working memory, are impaired after long-term heavy alcohol consumption. Neuropsychology 2004;18:203-11.

Hill SY, Wang S, Kostelnik B, Carter H, Holmes B, McDermott M, et al. Disruption of orbitofrontal cortex laterality in offspring from multiplex alcohol dependence families. Biol Psychiatry 2009;65:129-36.

Hofmann W, Gschwendner T, Wiers RW, Friese M, Schmitt M. Working memory capacity and self-regulatory behavior: towards an individual differences perspective on behavior determination by automatic versus controlled processes. J Pers Soc Psychol 2008;95:962-77.
Houben K, Wiers RW. Response inhibition moderates the influence of implicit associations on drinking behavior. Alcohol Clin Exp Res 2009;33:626-33.

Kalivas PW, Volkow ND. The neural basis of addiction: a pathology of motivation and choice. Am J Psychiatry 2005;162:1403-13.

Klingberg T, Fernell E, Olesen PJ, Johnson M, Gustafsson P, Dahlström K, et al. Computerized training of working memory in children with ADHD-a randomized, controlled trial. J Am Acad Child Adolesc Psych 2005;44:177-86.

Lees A, Mogg K, Bradley BP. Health anxiety, anxiety sensitivity, and attentional biases for pictorial and linguistic health-threat cues. Cogn Emot 2005;19:453-62.

Logan GD, Cowan WB. On the ability to inhibit thought and action: a theory of an act of control. Psychol Rev 1984;91:295-327.

Logan GD, Schachar RJ, Tannock R. Impulsivity and inhibitory control. Psychol Sci 1997;8:60-4.

Moselhy HF, Georgiou G, Kahn A. Frontal lobe changes in alcoholism: a review of the literature. Alcohol Alcohol 2001;36:357-68.

Nederkoorn C, Van Eijs Y, Jansen A. Restrained eaters act on impulse. Pers Individ Differ 2004;37:1651-8.

Nigg JT, Glass JM, Wong MM, Poon E, Jester JM, Fitzgerald HE, et al. Neuropsychological executive function in children at elevated risk for alcoholism: findings in early adolescence. J Abnorm Psychology 2004;113:302-14.

Nigg JT, Wong MM, Martel MM, Jester JM Puttler LJ, Glass JM, Adams KM, et al. Poor response inhibition as a predictor of problem drinking and illicit drug use in adolescents at risk for alcoholism and other substance use disorders. J Am Acad Child Adolesc Psych 2006;45:468-75.

Noël X, Van der Linden M, d'Acremont M, Colmant M, Hanak C, Pelc I, et al. Cognitive biases toward alcohol-related words and executive deficits in polysubstance abusers with alcoholism. Addiction 2005;100:1302-9.

Noël X, Van der Linden M, d'Acremont M, Bechara A, Dan B, Hanak C, et al. Alcohol cues increase cognitive impulsivity in individuals with alcoholism. Psychopharmacology 2007a;192:291-8.

Noël X, Dan B, Verbanck P. Alcohol cues compromise regulatory processes in recently detoxified alcoholics - reply to commentary. Psychopharmacology 2007b;192: $301-2$.

Patton JH, Stanford MS, Barratt ES. Factor structure of the Barratt Impulsiveness Scale. J Clin Psychol 1995;51:768-74.

Perry JL, Carroll ME. The role of impulsive behavior in drug abuse. Psychopharmacology 2008;200:1-26

Petry NM, Kirby KN, Kranzler HR. Effects of gender and family history of alcohol dependence on a behavioral task of impulsivity in healthy subjects. J Stud Alcohol 2002;63:83-90.

Piko BF. Adolescent smoking and drinking: the role of communal mastery and other social influences. Addict Behav 2006;31:102-14.

Rose AK, Duka D. Effects of alcohol on inhibitory processes. Behav Pharmacol 2008;19: 284-91.

Rubio G, Jimenez M, Rodriguez-Jimenez R, Martinez I, Iribarren MM, Jimenez-Arriero MA, et al. Varieties of impulsivity in males with alcohol dependence: the role of cluster-B personality disorder. Alcohol Clin Exp Res 2007;31:1826-32.

Saunders JB, Aasland OG, Babor TF, de la Fuente JR, Grant M. Development of the Alcohol Use Disorders Identification Test (AUDIT): World Health Organisation collaborative project on early detection of persons with harmful alcohol consumption-II. Addiction 1993;88:791-804.

Scheres A, Oosterlaan J, Swanson J, Morein-Zamir S, Meiran N, Schut H, et al. The effect of methylphenidate on three forms of response inhibition in boys with $\mathrm{AD} / \mathrm{HD}$. J Abnorm Child Psychol 2003;31:105-20.

Sher KJ, Walitzer KS, Wood PK, Brent EE. Characteristics of children of alcoholics: putative risk factors, substance use and abuse and psychopathology. J Abnorm Psychol 1991;100:427-48.

Sher KJ, Grekin ER, Williams NA. The development of alcohol use disorders. Ann Rev Clin Psychol 2005;1:493-523.

Sobell LC, Sobell MB. Self-report issues in alcohol abuse: state of the art and future directions. Behav Assess 1990;12:77-90.

Suls J, Green P. Pluralistic ignorance and college student perceptions of gender-specific alcohol norms. Health Psychol 2003;22:479-85.

Tarter RE, Kirisci L, Habeych M, Reynolds M, Vanyukov M. Neurobehavior disinhibition in childhood predisposes boys to substance use disorder by young adulthood: direct and mediated etiologic pathways. Drug Alcohol Depend 2004;73: 121-32.

Thush C, Wiers RW, Ames SL, Grenard JL, Sussman S, Stacy AW. Interactions between implicit and explicit cognition and working memory capacity in the prediction of alcohol use in at-risk adolescents. Drug Alcohol Depend 2008;94:116-24.

Townshend JM, Duka T. Attentional bias associated with alcohol cues: differences between heavy and occasional social drinkers. Psychopharmacology 2001;157:67-74.

Townshend JM, Duka T. Binge drinking, cognitive performance and mood in a population of young social drinkers. Alcohol Clin Exp Res 2005;29:317-25.

Verdejo-Garcia A, Lawrence AJ, Clark L. Impulsivity as a vulnerability marker for substance-use disorders: review of findings from high-risk research, problem gamblers and genetic association studies. Neurosci Biobehav Rev 2008;32:777-810.

von Diemen L, Bassani D, Fuchs S, Szobot C, Pechansky F. Impulsivity, age of first alcohol use and substance use disorders among male adolescents: a population based casecontrol study. Addiction 2008;103:1198-205.

Wiers RW, Hoogeveen KJ, Sergeant JA, Gunnning WB. High- and low-dose alcoholrelated expectancies and the differential associations with drinking in male and female adolescents and young adults. Addiction 1997;92:871-88.

Wiers RW, Gunning WB, Sergeant JA. Is a mild deficit in executive functions in boys related to childhood ADHD or to parental multigenerational alcoholism? J Abnorm Child Psychol 1998;26:415-30. 
Wiers RW, Bartholow BD, van den Wildenberg E, Thush C, Engels RVME, Sher KJ, et al. Automatic and controlled processes and the development of addictive behaviors in adolescents: a review and a model. Pharmacol Biochem Behav 2007;86:263-83.

Wiers RW, Rinck M, Dictus M, van den Wildenberg E. Relatively strong automatic appetitive action-tendencies in male carriers of the OPRM1 G-allele. Genes Brain Behav 2009;8:101-6.

Wilens TE, Faraone SV, Biederman J, Gunawardene S. Does stimulant therapy of attention-deficit/hyperactivity disorder beget later substance abuse? A metaanalytic review of the literature. Pediatrics 2003;111:179-85.
Wilhelm CJ, Reeves JM, Phillips TJ, Mitchell SH. Mouse lines selected for alcohol consumption differ on certain measures of impulsivity. Alcohol Clin Exp Res 2007;31: 1839-45.

Zilberman M, Tavares H, el Guebaly N. Gender similarities and differences: the prevalence and course of alcohol- and other substance-related disorders. J Addict Dis 2003;22:61-74. 